\title{
Allometric equations for estimating on-farm fuel production of Gliricidia sepium (Gliricidia) shrubs and Cajanus cajan (pigeon pea) plants in semi-arid Tanzania
}

J. M. Hafner ${ }^{1,2^{*}}$ (D) J. Steinke ${ }^{1,3}$, G. Uckert ${ }^{1}$, S. Sieber ${ }^{1,3}$ and A. A. Kimaro ${ }^{2}$

\begin{abstract}
Background: Fuelwood is considered to be the primary source of cooking energy in Tanzania and, due to ongoing deforestation, access to fuelwood is becoming more cumbersome. On-farm agroforestry systems can reduce dependency on off-farm fuel; however, the output of on-farm produced fuel is typically uncertain as production potentials are often not known. In this paper, we have developed allometric equations to model the above-ground woody biomass (AGWB) production from intercropped Gliricidia sepium (Jacq.) Kunth ex Walp (Gliricidia) shrubs and Cajanus cajan (L.) Millsp. (pigeon pea) plants.
\end{abstract}

Methods: We used a destructive sampling approach, for measuring the dendrometric characteristics, such as the root collar diameter at a $20 \mathrm{~cm}$ stem height $\left(\mathrm{RCD}_{20}\right)$ and the stem height to estimate the AGWB production. The models are based on 112 Gliricidia and 80 pigeon pea observations from annually pruned plants. Seven allometric equations were fitted to derive the best-fit models for the AGWB production.

Results: We found that using a natural log-transformed linear model with $\mathrm{RCD}_{20}$ as a single predictor variable provides the highest explanatory value to estimate the AGWB production (Gliricidia: $R^{2}=95.7 \%$, pigeon pea: $R^{2}=91.4 \%$ ) while meeting Ordinary Least Square (OLS) estimator requirements. Adding stem height as an additional variable to predict the AGWB production does not improve model accuracy enough to justify the extra work for including it.

Conclusions: While on-farm pigeon pea plants produced a stable amount of woody biomass per annum, annual fuelwood production from Gliricidia shrubs increased over the years. Compared to the annual fuelwood consumption data from the literature, our results show that on-farm produced fuelwood can substantially offset the demand for off-farm fuel, potentially resulting in household fuelwood autarky.

Keywords: Agroforestry, Intercropping, Energy self-sufficiency, Smallholder farmer, Energy mix, Food security

\footnotetext{
*Correspondence: johanneshafner@gmx.net

${ }^{1}$ Leibniz Centre for Agricultural Landscape Research (ZALF), Research

Area "Land Use and Governance", Eberswalder Str. 84, 15374 Müncheberg, Germany

Full list of author information is available at the end of the article
}

\section{Background}

Most rural households in Tanzania depend on wood fuel from the remaining forests. A reported annual loss of forest and woodlands of more than 370,000 ha year ${ }^{-1}$ challenges rural populations as they must cover ever increasing distances to collect fuelwood that meets their energy demands $[1,2]$. This especially affects women and permits use, sharing, adaptation, distribution and reproduction in any medium or format, as long as you give appropriate credit to the original author(s) and the source, provide a link to the Creative Commons licence, and indicate if changes were made. The images or other third party material in this article are included in the article's Creative Commons licence, unless indicated otherwise in a credit line to the material. If material is not included in the article's Creative Commons licence and your intended use is not permitted by statutory regulation or exceeds the permitted use, you will need to obtain permission directly from the copyright holder. To view a copy of this licence, visit http://creativecommons.org/licenses/by/4.0/. The Creative Commons Public Domain Dedication waiver (http://creativeco mmons.org/publicdomain/zero/1.0/) applies to the data made available in this article, unless otherwise stated in a credit line to the data. 
children who are mainly responsible for collecting wood fuel.

The situation is aggravated by the fact that most smallholder farmers in rural Tanzania use unimproved cooking devices to cook their daily food [3], which reportedly consume more fuel than Improved Cook Stoves (ICS). Studies have shown that fuel scarcity leads to shifting cooking habits, including skipping meals, cooking composite meals, reducing the number of cooked meals per day, and cooking fast meals, which are often nutrientpoor [2, 4]. Around $80 \%$ of the Tanzanian population depends on fuelwood to meet domestic needs, including cooking, boiling water, lighting, and heating [5]. The rapid population growth in Tanzania and across East Africa is intensifying the challenge for smallholder farmers to meet their domestic energy needs [6, 7]. While slashand-burn agricultural practices might be more profitable in the short-term, agroforestry practices can create income in the medium- or long-term run [8]. Enlarging farmlands to meet food and domestic energy demands is not a sustainable solution and might entail enormously negative socio-economic effects. Food security is a challenge and connected to stagnating productivity of crop production [9]. Funk and Brown [7] have demonstrated that the area for agricultural production in East Africa has been enhanced by $55 \%$ since 1980 , while at the same time, agricultural yields only increased by $25 \%$ [10]. The impact of fuel security to meet domestic cooking energy demand and its impact on households' food security is often neglected.

Agroforestry systems can benefit small-scale farmers, not only enhancing soil fertility but also contributing to fuelwood production and reducing household dependency on fuelwood from external sites [11] without compromising crop production [12]. While socio-economic benefits are connected to on-farm fuel production at the household level, reduced forest degradation and deforestation have positive effects on a global scale, with forests being the major above-ground carbon sink [13].

Both on-farm tree plantations and the use of crop residues are promoted to enhance rural households' energy supply, making households energy consumption more sustainable [14, 15]. However, the use of on-farm fuels is limited by obstacles such as the lack of access to tree seedlings and limited skills to manage on-farm trees. Onfarm fuel production is often seen as a trade-off decision with respect to planting food crops. Smallholder farmers usually operate with limited financial resources. For making cost-benefit efficient decisions, it is important to determine the fuel production potential of on-farm fuels to meet the domestic energy demand. Farmers and other stakeholders can be supported in decision making with reliable allometric models that estimate costs and area requirements to produce on-farm wood.

There are several ways to estimate the above-ground biomass production of plants [16-18]: (i) Physiologicalbased models estimate tree biomass based on site-specific information such as temperature, rainfall and solar radiation; (ii) destructive sampling approaches assessing physical factors such as stem diameter, stem height and weight of plants used to develop optimized (site-specific) allometric equations to model biomass production; and (iii) non-destructive methods using existing allometric equations to estimate biomass production after having been adapted to fit the site and species characteristics of the tree. Other non-destructive methods use remote sensing via satellite or drone images to estimate stem height and canopy dimensions to develop allometric equations.

While non-destructive approaches are less labourintensive than invasive field-based approaches, they might lead to imprecise results due to differing site conditions $[19,20]$. Destructive sampling methods are an often used approach to determine the relationship between dependent and independent variables to develop allometric equations [21,22], where allometric equations are missing.

While models that attempt to estimate the aboveground woody biomass (AGWB) production of on-farm fuels are available for pigeon pea [23], models to estimate the AGWB production of Gliricidia are not yet established. As allometric equations are species-specific, it is necessary to develop and adjust equations [19]. Most allometric equations use the relationship between the independent variables, such as stem diameter and/ or stem height, and the dependent variables, such as wood and foliage biomass [24]. Often linear and non-linear regression models using arithmetic or log-transformed data are applied [25].

The integration of on-farm trees in cropping regimes changes landscapes and farm management schemes. In this paper, we have developed initial allometric models for estimating the AGWB production potential of Gliricidia and pigeon pea under different cropping scenarios in semi-arid regions in Tanzania. We have assessed the dendrometric variables, such as the root collar diameter at a $20 \mathrm{~cm}$ stem height $\left(\mathrm{RCD}_{20}\right)$, the stem height and the AGWB for estimating the AGWB production. The developed allometric models provide decision support for stakeholders to plan the on-farm AGWB production and allow a non-destructive determination of pigeon pea and Gliricidia fuelwood optimizing planting and management decisions. As the allometric models are based upon empirically assessed data, they can be applied to other 
sites with similar crop and site conditions, thus being widely useful.

\section{Materials and methods Case study site}

The case study site is located at Manyusi, $1206 \mathrm{~m}$ above sea level (m.a.s.l.), Dodoma region, Tanzania (Fig. 1). Between 1981 and 2010, the average annual rainfall in the region was $590.6 \mathrm{~mm}$. While the overall rainfall declined by $4 \%$ over the observation period, erratic rainfall poses an incalculable risk for smallholder farmers [26]. Most people in rural areas use unimproved Three-Stone-Fire stoves (TSF) to cook and prepare food.

\section{Experimental design}

The research trial was established at the onset of the cropping year in 2015. The onset of a cropping year is usually in late December/early January; Maize is harvested in June or July, while pigeon pea is harvested in September. In total, we analysed four different pigeon pea and Gliricidia fuel production systems in a randomized complete block design (RCBD) to determine fuel production under different cropping systems with varying plant densities (Fig. 2):

- Cropping system 1 (Sole pigeon pea=PP): Pigeon pea was planted as a monoculture. Pigeon pea was planted with a spacing of $0.75 \mathrm{~m}$ between and $0.6 \mathrm{~m}$ within pigeon pea rows.

- Cropping system 2 (Intercropped maize and pigeon pea =MPP): Maize and pigeon pea were intercropped. Maize and pigeon pea rows were planted with a spacing of $0.75 \mathrm{~m}$ between the rows and $0.6 \mathrm{~m}$ within the rows in an additive series design. Applying an additive system, pigeon pea plants were planted between maize plants; doubling the number of crops per unit area compared to cropping system 1 .

- Cropping system 3 (Intercropped maize, pigeon pea and Gliricidia =MPPGS): Maize, pigeon pea, and Gliricidia were intercropped. Maize and pigeon pea plants were planted with a spacing of $0.75 \mathrm{~m}$ between the rows and $0.6 \mathrm{~m}$ within the rows, in an additive system by doubling the number of crops compared to cropping system 1. Gliricidia plants were intercropped with a spacing of $4 \mathrm{~m}$ by $4 \mathrm{~m}$ between and within the rows.

- Cropping system 4 (Intercropped maize and Gliricidia=MGS): Maize and Gliricidia were intercropped. Maize was planted with a spacing of $0.75 \mathrm{~m}$ between the rows and $0.6 \mathrm{~m}$ within the rows. The Gliricidia plants were intercropped with a spacing of $4 \mathrm{~m}$ by $4 \mathrm{~m}$ between and within the rows.
Gliricidia was coppiced twice a year. The first pruning was done at the onset of crop planting; harvested wood was primarily used as fuelwood. Upon cutting and removing Gliricidia, the crops were planted. Depending on the rainfall, the second pruning of Gliricidia was done 6-9 weeks after planting. The green stems and foliage remained on the plots to serve as an organic fertilizer. To reduce competition between crops and weeds, weeding was carried out three times within a cropping season using hand hoes. After harvesting pigeon pea grains, the plants were removed and replanted at the onset of the following cropping year.

\section{Data collection and development of allometric models to estimate above-ground woody biomass}

In a first step, we destructively sampled Gliricidia and pigeon pea to determine $\mathrm{AGWB}^{1}$ (Table 1). The samples for establishing the allometric equations to estimate the AGWB were obtained from Gliricidia and pigeon pea stems from the research plot. The data collected to develop the allometric equations were assessed in years 5 and 6 to assess the growth patterns of crops after Gliricidia plants had been properly established. The $\mathrm{RCD}_{20}$ and stem height variables were selected as independent variables to describe the AGWB production. We corrected the data set to remove outliers, all connected to incorrect measurement or data recording.

Moisture content of Gliricidia and pigeon pea was measured to estimate the dry-weight woody biomass production per plant. The fresh samples were ovendried to achieve the dry weight of the samples. In total, 45 wood cookies were selected from different Gliricidia stems to determine the moisture content of freshly cut Gliricidia. The Gliricidia plants were sampled before the crop planting to avoid competition between the crops and the shrubs. Three cookies per stem were sampled from different parts of the stem $(30 \mathrm{~cm}$ from the ground, from the middle and $30 \mathrm{~cm}$ from the top of the stem) that had an approximate length of $2 \mathrm{~cm}$ to $3 \mathrm{~cm}$. The water content was calculated by dividing the water weight in grams by the total weight of the freshly cut wood. The average water content per Gliricidia cookie was $64.0 \%$ (SD 2.1). To determine the water and dry matter content of pigeon pea stalks, we selected 44 whole plants after the pigeon pea grain was harvest and calculated the water content based upon the relationship between the fresh weight and the absolute dry weight of pigeon pea stalks. The average water content per sample amounted to $50.0 \%$ (SD 6.3).

${ }^{1}$ Note: We present the weight of AGWB at zero moisture content. 


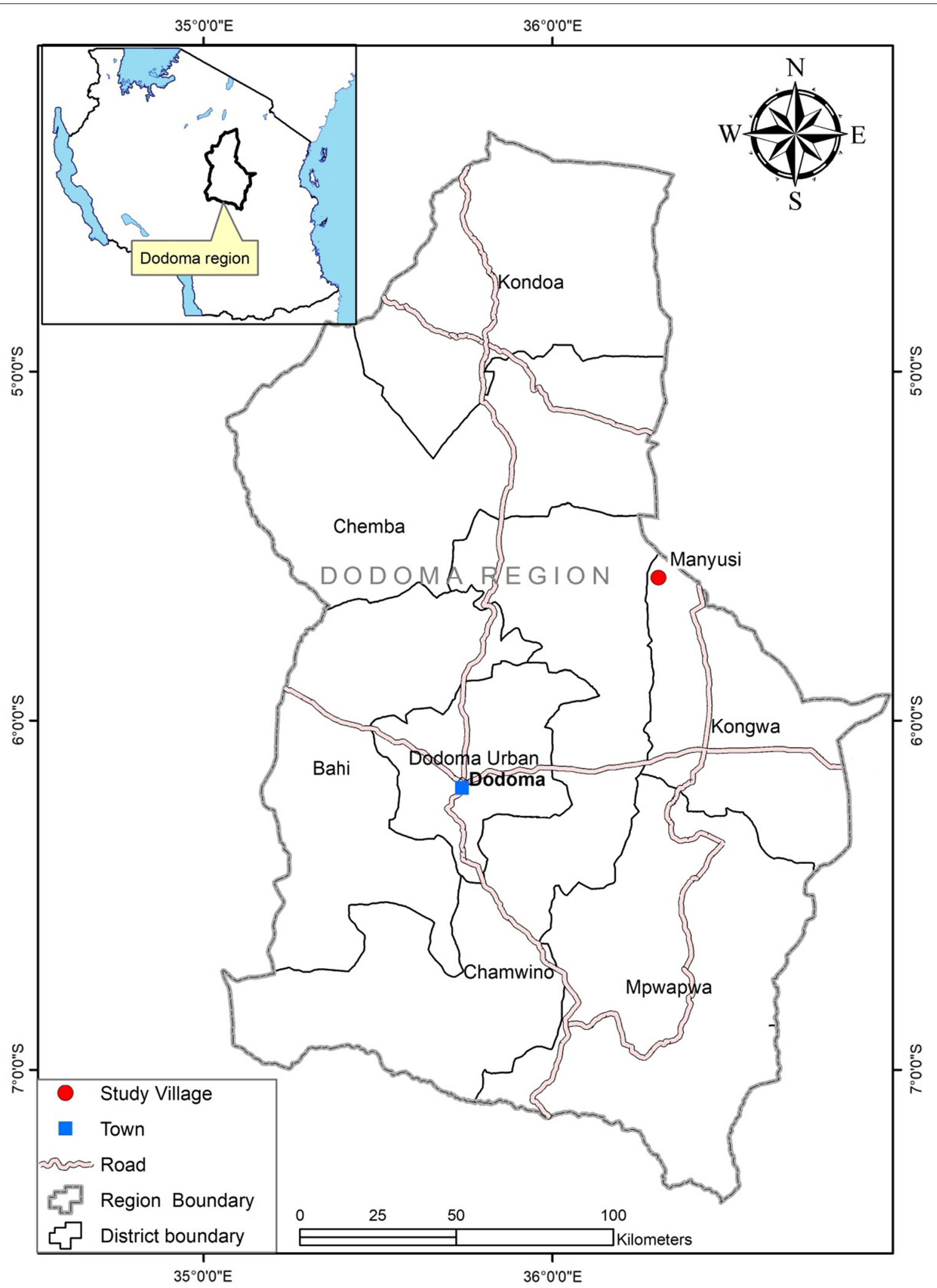

Fig. 1 Map of the Dodoma region, Tanzania, with the case study site Manyusi 

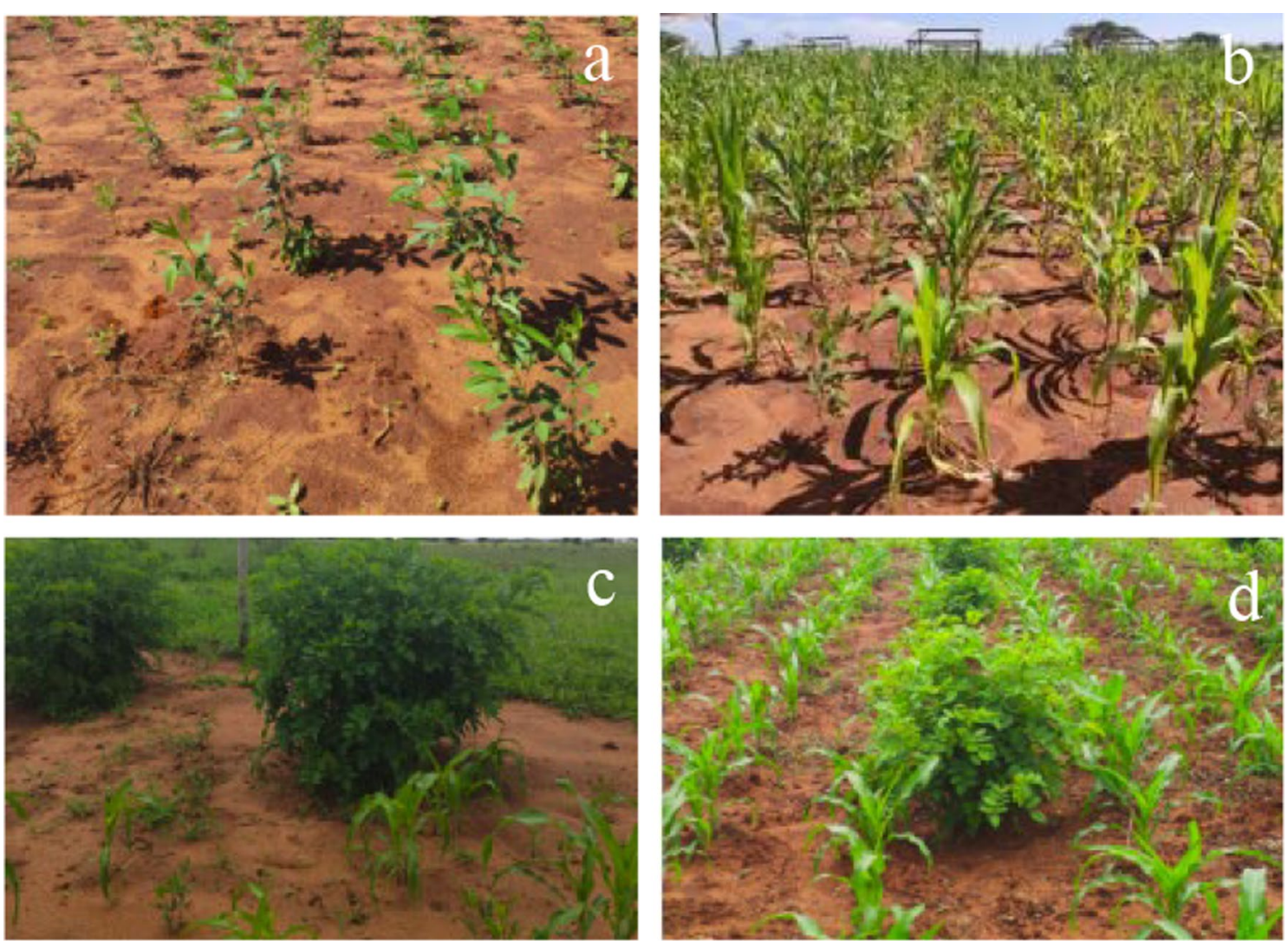

Fig. 2 Cropping system 1: PP (a), cropping system 2: MPP (b), cropping system 3: MPPGS (c), cropping system 4: MGS (d) at Manyusi village, Kongwa District, Dodoma, Tanzania

Table 1 Dendrometric variables of pigeon pea and Gliricidia at Manyusi village, Kongwa District, Dodoma, Tanzania

\begin{tabular}{|c|c|c|c|c|c|c|c|c|}
\hline & \multicolumn{4}{|c|}{ Pigeon pea $(n=80)$} & \multicolumn{4}{|c|}{ Gliricidia $(n=112)$} \\
\hline & Mean & SD & Min & Max & Mean & SD & Min & Max \\
\hline $\mathrm{RCD}_{20}(\mathrm{~cm})$ & 1.87 & 0.37 & 1.19 & 2.94 & 2.70 & 0.75 & 0.67 & 3.93 \\
\hline Stem height $(\mathrm{cm})$ & 244 & 34 & 123 & 294 & 271 & 93 & 63 & 464 \\
\hline AGWB (gram) & 238 & 135 & 78 & 788 & 452 & 265 & 18 & 1448 \\
\hline
\end{tabular}

After fitting different arithmetic (non-linear) and natural log-transformed (linear) models to estimate the AGWB per plant, we evaluated the models with regard to the coefficient of determination $\left(R^{2}\right)$ and the Akaike information criterion (AIC) to select the best models [27]. By definition AIC "penalizes" models that use additional unnecessary parameters [28]. The non-linear models (1-3) were transformed into linear models (4-7) using the natural logarithm to meet assumptions for linear regression. To use the ordinary least-square (OLS) estimator, we checked whether the natural logtransformed data meet the conditions for linear regression. Therefore, we tested the assumptions of normal distribution of error terms, constant variance of error terms (homoscedasticity) and multicollinearity of $\mathrm{RCD}_{20}$ and stem height.

$$
\begin{aligned}
& \operatorname{AGWB}(\mathrm{g})=\mathrm{a} * \mathrm{RCD}_{20}^{\mathrm{b}} \\
& \operatorname{AGWB}(\mathrm{g})=\mathrm{a} * \text { Stem height } \\
& \operatorname{AGWB}(\mathrm{g})=\mathrm{a} * \mathrm{RCD}_{20}^{\mathrm{b}} * \text { Stem heig } \\
& \text { Ln_AGWB }=\mathrm{a}+\mathrm{b} * \ln \left(\mathrm{RCD}_{20}\right)
\end{aligned}
$$$$
\text { AGWB }(\mathrm{g})=\mathrm{a} * \mathrm{RCD}_{20}^{\mathrm{b}} * \text { Stem height }^{\mathrm{c}} \quad(\text { Model 3) }
$$

(Model 4) 


$$
\begin{aligned}
& \text { Ln_AGWB }=\mathrm{a}+\mathrm{b} * \ln (\text { Stem height }) \\
& \text { (Model 5) } \\
& \mathrm{Ln \_ AGWB}=\mathrm{a}+\mathrm{b} * \ln \left(\mathrm{RCD}_{20}\right)+\mathrm{c} * \ln \left(\begin{array}{c}
\text { Stem height }) \\
\text { (Model 6) }
\end{array}\right. \\
& \mathrm{Ln \_ ABWG}=\mathrm{a}+\mathrm{b} * \ln \left(\mathrm{RCD}_{20} * \text { Stem height }\right)
\end{aligned}
$$

with Ln denoting the natural logarithm; $a, b$, and $c$ denote the constant numbers developed based upon 80 pigeon pea and 112 Gliricidia samples.

The estimated biomass was corrected using a correction factor (CF) accounting for the bias connected to the $\log$ transformation. During the back-transformation of logarithmic to arithmetic values, median values instead of mean values were introduced, which leads to an underestimation of results [29]. To minimize this error, the antilog of the logarithmic value of the AGWB was multiplied with the CF [30]:

$$
C F=\exp \left(\frac{S E E^{2}}{2}\right)
$$

where SEE denotes the standard error of the estimated model.

Likewise, we compared the allometric models with the control groups of each cropping system and found that the AGWB estimation with model 4 provides estimates closest to the measured parameters. Model 4 has the highest prediction value using a single predictor variable $\left(\mathrm{RCD}_{20}\right)$ and should be recommended for application by stakeholders in the field. The AGWB production of pigeon pea per area was calculated based on assessments of the dendrometric variables in cropping years 5 and 6 . The independent variables $R C D_{20}$ and stem height were assessed to predict the AGWB per plant. In total, we assessed the dendrometric variables of 131 (Cropping system 1, PP), 130 (Cropping system 2, MPP), and
102 (Cropping system 3, MPPGS) pigeon pea plants in a pre-defined area. Based upon the developed allometric models, we used the variable $R C D_{20}$ as a single variable to predict the AGWB production (model 4).

The extrapolation of the AGWB production of Gliricidia per area was based on the measurements of the current AGWB production per area in the cropping years 4, 5, 6 and 7. Each year, 73 Gliricidia plants under cropping system 3 (MPPGS) and 75 Gliricidia plants under cropping system 4 (MGS) were assessed.

\section{Results}

Allometric modelling of the above-ground woody biomass production of pigeon pea and Gliricidia

Before developing allometric equations for predicting the AGWB production of pigeon pea and Gliricidia, we plotted the relationship between the independent variables ( $\mathrm{RCD}_{20}$ and stem height) and the dependent variable (AGWB). Linear natural log-transformed models had higher explanatory values compared to non-linear models using the same variables. A visual assessment of natural log-transformed variables indicates a strong relationship between the $\mathrm{RCD}_{20}$ and the AGWB. The relationship between the natural log-transformed values for the stem height and the AGWB does not show a comparably strong linear relationship (Figs. 3 and 4).

The non-linear models (models 1-3) are able to explain the variation in the AGWB production of pigeon pea and Gliricidia to a high degree. However, with higher values of the explanatory values (exceeding the measured boundaries of $\mathrm{RCD}_{20}$ and stem height), the estimation of the AGWB production becomes more imprecise. Our findings demonstrate that natural log-transformed allometric models are more suitable to explain the AGWB production as their variables are linearised. The models meet the requirements of the OLS estimator for linear

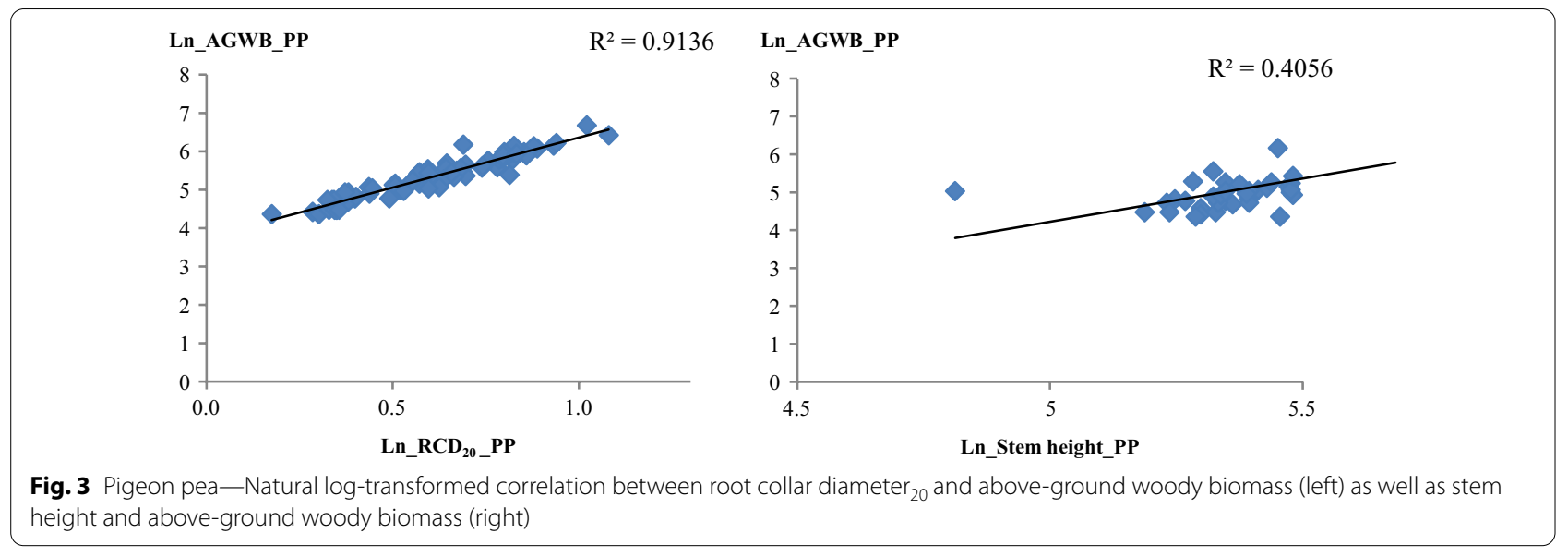



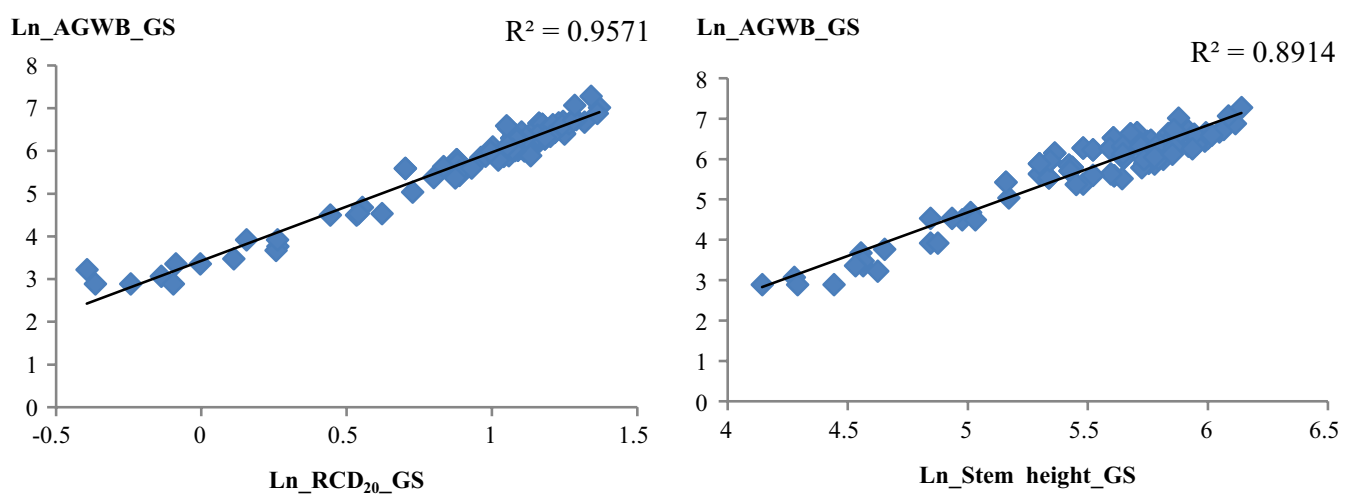

Fig. 4 Gliricidia-Natural log-transformed correlation between root collar diameter 20 and above-ground woody biomass (left) as well as stem height and above-ground woody biomass (right)

Table 2 Allometric models for estimating the above-ground woody biomass of pigeon pea

\begin{tabular}{|c|c|c|c|c|c|c|c|c|}
\hline \multirow[t]{2}{*}{ Model no. } & \multicolumn{3}{|c|}{ Regression coefficients } & \multirow[t]{2}{*}{ SEE } & \multirow[t]{2}{*}{$\mathrm{CF}$} & \multirow[t]{2}{*}{$p$ value } & \multirow[t]{2}{*}{$R^{2}(\%)$} & \multirow[t]{2}{*}{ AIC } \\
\hline & a & b & c & & & & & \\
\hline 1 & 43.691 & 2.590 & & * & * & $* *$ & 88.5 & $* *$ \\
\hline 2 & $1.377 * 10^{-5}$ & 3.022 & & * & * & $* *$ & 39.7 & $* *$ \\
\hline 3 & 5.989 & 2.459 & 0.376 & * & * & $* *$ & 88.9 & $* *$ \\
\hline 4 & 3.753 & 2.604 & & 0.159 & 1.013 & $<0.001$ & 91.4 & -292 \\
\hline 5 & -7.18 & 2.281 & & 0.418 & 1.091 & $<0.001$ & 40.6 & -138 \\
\hline 6 & 0.918 & 1.283 & 0.367 & 0.164 & 1.014 & $<0.001$ & 90.9 & -286 \\
\hline 7 & -1.459 & 1.014 & & 0.178 & 1.016 & $<0.001$ & 89.2 & -274 \\
\hline
\end{tabular}

$\mathrm{a}, \mathrm{b}, \mathrm{c}$ are constant numbers

*The standard error of estimate (SEE) and CF are not relevant for non-linear regression models

**The calculation of $p$ values and AIC is not applicable for non-linear models

Table 3 Allometric models for estimating the above-ground woody biomass of Gliricidia

\begin{tabular}{|c|c|c|c|c|c|c|c|c|}
\hline \multirow[t]{2}{*}{ Model no. } & \multicolumn{3}{|c|}{ Regression coefficients } & \multirow[t]{2}{*}{ SEE } & \multirow[t]{2}{*}{ CF } & \multirow[t]{2}{*}{$p$ value } & \multirow[t]{2}{*}{$\mathrm{R}^{2}(\%)$} & \multirow[t]{2}{*}{ AIC } \\
\hline & a & b & c & & & & & \\
\hline 1 & 23.548 & 2.805 & & * & * & $* *$ & 87.0 & $* *$ \\
\hline 2 & 0.060 & 1.587 & & * & * & $* *$ & 73.8 & $* *$ \\
\hline 3 & 2.928 & 2.202 & 0.482 & * & * & $* *$ & 88.8 & $* *$ \\
\hline 4 & 3.427 & 2.540 & & 0.207 & 1.022 & $<0.001$ & 95.7 & -351 \\
\hline 5 & -6.117 & 2.159 & & 0.330 & 1.059 & $<0.001$ & 89.1 & -246 \\
\hline 6 & 0.494 & 1.865 & 0.646 & 0.177 & 1.016 & $<0.001$ & 96.9 & -386 \\
\hline 7 & -0.332 & 0.830 & & 0.179 & 1.016 & $<0.001$ & 96.8 & -384 \\
\hline
\end{tabular}

$\mathrm{a}, \mathrm{b}, \mathrm{c}$ are constant numbers

*The SEE and CF are not relevant for non-linear regression models

**The calculation of $p$ values and AIC is not applicable for non-linear models 
regression. For all linear models (models 4-7), the analysis reveals that there is a statistically significant relationship $(p<0.001)$ between the independent variables $\left(\mathrm{RCD}_{20}\right.$ and stem height) and the dependent variable (AGWB) for pigeon pea and Gliricidia (Tables 2 and 3).

With regard to pigeon pea, the arithmetic model 1 using the independent variable $\mathrm{RCD}_{20}$ explains more than $88.5 \%$ of the variation in the AGWB production. Combined with the independent stem height variable, the explanatory value $\left(R^{2}=88.9 \%\right)$ of the exponential model is slightly higher (model 3). With regard to the AGWB production of pigeon pea in natural log-transformed linear allometric models (Models 4-7), the $\mathrm{RCD}_{20}$ is the best predictor for the AGWB production when considering the degree of determination as well as the AIC. With the independent variable $\mathrm{RCD}_{20}, 91.4 \%$ of the variance of the AGWB production (model 4) can be explained. Combined with $\mathrm{RCD}_{20}$, stem height was a good supplementary explanatory variable to explain the AGWB $\left(R^{2}=90.9 \%\right)$ (Model 6). However, a combination of $\mathrm{RCD}_{20}$ and stem height does not reach the explanatory power of using $\mathrm{RCD}_{20}$ as a single predictor. In addition, multicollinearity occurs with regard to the independent variables $\mathrm{RCD}_{20}$ and stem height. To avoid multicollinearity among independent variables, $\mathrm{RCD}_{20}$ and stem height were commuted as a composite variable to explain the AGWB production (Model 7). The resulting model has a lower explanatory power (89.2\%) than models 4 and 6.

Stem height alone is not a good predictor for the AGWB, either using the exponential model $\left(R^{2}=39.7 \%\right)$ (Model 2) or the natural log-transformed linear model $\left(R^{2}=40.6 \%\right)$ (Model 5).

With regard to AGWB production of Gliricidia, we detected that $R C D_{20}$ is a strong predictor for biomass using both non-linear (1-3) and natural log-transformed linear allometric models (Models 4-7). Across the arithmetic models (Models 1-3), $\mathrm{RCD}_{20}$ and stem height could explain the variation of the AGWB production best $\left(R^{2}=88.8 \%\right.$ ) (Model 3$)$, followed by $\mathrm{RCD}_{20}$ as a single predictor $\left(R^{2}=87.0 \%\right)$ (Model 1$)$.

The linear natural log-transformed models (4-7) meet the statistical criteria of the OLS for estimating the AGWB production. $\mathrm{RCD}_{20}$ used as a single predictor is also a very good predictor $\left(R^{2}=95.7 \%\right)$ for estimating AGWB (Model 4). We observed that a combination of $\mathrm{RCD}_{20}$ and stem height provides the highest explanatory value for estimating AGWB $\left(R^{2}=96.9 \%\right)$ (Model 6). However, as in the pigeon pea modelling case, multicollinearity exists between $\mathrm{RCD}_{20}$ and stem height. Therefore, $\mathrm{RCD}_{20}$ and stem height was tested as a composite variable for predicting the AGWB production $\left(R^{2}=96.8 \%\right)$ (Model 7).
For estimating the AGWB production of Gliricidia, stem height is a much better predictor than it is for the AGWB production of pigeon pea. Using the non-linear model (Model 2), stem height explains $73.8 \%$ of the variation, while for the linear natural log-transformed model, stem height explains $89.1 \%$ of the variation (Model 5). However, the models are still outperformed by allometric models using $\mathrm{RCD}_{20}$ as a single predictor variable or in combination with stem height to predict the AGWB production.

\section{Estimating the above-ground woody biomass production of pigeon pea and Gliricidia}

The assessment of the AGWB production of pigeon pea shows that cropping system 3 (MPPGS) with three crops has lower crop survival rates compared to cropping systems 1 (PP) and 2 (MPP), indicating a declining survival rate of pigeon pea plants with higher plant density per area. In general, the survival rates were higher in cropping year 5 than in cropping year 6 . The AGWB production per plant was highest at $109 \mathrm{~g}$ when using cropping system 1 versus $84 \mathrm{~g}$ when using cropping system 2 and $94 \mathrm{~g}$ when using cropping system 3 . The mean diameter of the pigeon pea stems $\left(\mathrm{RCD}_{20}\right)$ under cropping system 1 was $9 \%$ and $6 \%$ larger compared to cropping systems 2 and 3, respectively. The AGWB production was 23\% (Cropping system 2) and 33\% (Cropping system 3) less than with cropping system 1. Comparing the AGWB production between cropping year 5 (2019) and cropping year 6 (2020), we observed that the AGWB differed largely within the cropping systems. While the AGWB production per $\mathrm{m}^{2}$ declined by $16 \%$ for cropping system 1 between cropping years 5 and 6 , the AGWB production increased by $50 \%$ for cropping system 2 and $79 \%$ for cropping system 3 , respectively (Table 4).

With regard to Gliricidia, we standardised the AGWB production of the Gliricidia shrubs to $\mathrm{m}^{2}$ for comparing it with the pigeon pea production. The survival rates of Gliricidia shrubs are much higher than those of pigeon pea. The AGWB production per Gliricidia plant within the first 3 years can be neglected due to low production. However, between cropping years 4 and 7 , the AGWB production per Gliricidia plant grew. The absolute AGWB production was higher when using cropping system 4 (MGS) instead of cropping system 3. During cropping year 4, 87\% more AGWB of Gliricidia was produced when using cropping system 4 compared to cropping system 3 . This relative difference in annual AGWB production was reduced each year up to $51 \%$ in cropping year 7 (Table 5).

Based upon the AGWB production per plant of pigeon pea and Gliricidia, we estimated the production potential at a hectare basis. For pigeon pea, we used the mean AGWB production per subplot of cropping years 5 and 6 as a proxy to estimate the production per 
Table 4 Survival rates, subplot size, root collar diameter 20 , and the above-ground woody biomass production of pigeon pea per $\mathrm{m}^{2}$

\begin{tabular}{|c|c|c|c|c|c|c|}
\hline \multicolumn{7}{|l|}{ Cropping year: 5 (2019) } \\
\hline & $\begin{array}{l}\text { Survival rates } \\
\text { (\%) }\end{array}$ & $\begin{array}{l}\text { Subplot area } \\
\left(\mathrm{m}^{2}\right)\end{array}$ & $\mathrm{RCD}_{20} \min (\mathrm{cm})$ & $\mathrm{RCD}_{20} \max (\mathrm{cm})$ & $\begin{array}{l}\text { Mean } \mathrm{RCD}_{20} \\
(\mathrm{~cm})\end{array}$ & 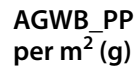 \\
\hline C/system 1: PP $(n=61)$ & 85 & 16.2 & 0.77 & 2.02 & 1.36 & 390 \\
\hline C/system 2: MPP $(n=59)$ & 82 & 16.2 & 0.59 & 1.59 & 1.07 & 209 \\
\hline C/ system 3: MPPGS $(n=50)$ & 69 & 16.2 & 0.81 & 1.55 & 1.06 & 161 \\
\hline \multicolumn{7}{|l|}{ Cropping year: 6 (2020) } \\
\hline & $\begin{array}{l}\text { Survival rates } \\
\text { (\%) }\end{array}$ & $\begin{array}{l}\text { Subplot area } \\
\left(\mathrm{m}^{2}\right)\end{array}$ & $\mathrm{RCD}_{20} \mathrm{~cm}(\mathrm{~min})$ & $\mathrm{RCD}_{20} \mathrm{~cm}(\max )$ & $\begin{array}{l}\text { Mean } \mathrm{RCD}_{20} \\
(\mathrm{~cm})\end{array}$ & 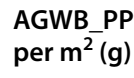 \\
\hline C/system 1: PP $(n=70)$ & 65 & 24.3 & 0.64 & 2.63 & 1.32 & 328 \\
\hline C/system 2: MPP $(n=71)$ & 66 & 24.3 & 0.81 & 2.55 & 1.36 & 313 \\
\hline C/system 3: MPPGS $(n=52)$ & 48 & 24.3 & 0.66 & 2.37 & 1.46 & 288 \\
\hline \multicolumn{7}{|c|}{ Cropping year: 5 (2019) and 6 (2020) } \\
\hline & $\begin{array}{l}\text { Survival rates } \\
\text { (\%) }\end{array}$ & $\begin{array}{l}\text { Subplot area } \\
\left(\mathrm{m}^{2}\right)\end{array}$ & $\mathrm{RCD}_{20} \mathrm{~cm}(\mathrm{~min})$ & $\mathrm{RCD}_{20} \mathrm{~cm}(\max )$ & $\begin{array}{l}\text { Mean } \mathrm{RCD}_{20} \\
(\mathrm{~cm})\end{array}$ & 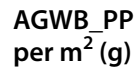 \\
\hline C/system 1: PP $(n=131)$ & 75 & 40.5 & 0.64 & 2.63 & 1.34 & 353 \\
\hline C/system 2: MPP $(n=130)$ & 74 & 40.5 & 0.59 & 2.55 & 1.22 & 271 \\
\hline C/system 3: MPPGS $(n=102)$ & 59 & 40.5 & 0.66 & 2.37 & 1.26 & 237 \\
\hline
\end{tabular}

Table 5 Survival rates, subplot size, root collar diameter ${ }_{20}$, and the above-ground woody biomass production of Gliricidia per $\mathrm{m}^{2}$

\begin{tabular}{|c|c|c|c|c|c|c|}
\hline & \multirow[t]{2}{*}{ Survival rates (\%) } & \multirow[t]{2}{*}{ Subplot area $\left(\mathrm{m}^{2}\right)$} & \multicolumn{4}{|c|}{ AGWB_GS per $\mathrm{m}^{2}$ per cropping year (g) } \\
\hline & & & 4 (2018) & 5 (2019) & $6(2020)$ & $7(2021)$ \\
\hline C/system 3: MPPGS ( $n=75)$ & 100 & 1200 & 18 & 63 & 69 & 250 \\
\hline C/system 4: MGS ( $n=73)$ & 97 & 1200 & 33 & 117 & 114 & 378 \\
\hline
\end{tabular}

hectare. Particularly in the early years, cropping systems 1, 2 and 3 are superior with regard to the AGWB production compared to sole maize and Gliricidia intercropping (Cropping system 4) due to the stable AGWB production of pigeon pea. While the AGWB production of cropping systems 1 and 2 do not change over time, the overall AGWB production of cropping systems 3 and 4 rose due to the re-growing Gliricidia stock. At the end of the observation period (Cropping year 7), cropping system 3 with a combined AGWB production of pigeon pea and Gliricidia demonstrated the highest AGWB output across all production systems. The AGWB production of cropping system 3 exceeded the AGWB production of cropping system 1 by $38 \%$, cropping system 2 by $79 \%$ and cropping system 4 by $29 \%$, respectively (Fig. 5).

\section{Discussion}

Data collection and allometric models for estimating the above-ground woody biomass production

There are a variety of models that attempt to estimate the above-ground biomass from plants in sub-Saharan
Africa (SSA) [31]. Destructive or non-destructive assessments are used to develop allometric equations that predict the biomass production of plants [32]. A prominent resource-efficient method for estimating larger areas of forested land is remote sensing, which focuses on analysing tree canopy data [33]. However, because we estimated the allometric equations from annually pruned plants, the remote assessment of the canopy was not feasible as canopies of annual plants have not been established. Therefore, we used a destructive sampling approach to assess dendrometric variables such as $R \mathrm{CD}_{20}$ and stem height for estimating the AGWB. Destructive sampling approaches provide accurate information on relevant growth variables; however, the method is very resourceintensive with regard to labour and time required for collecting the data [34].

We assessed the dendrometric variables of annually pruned Gliricidia and pigeon pea plants in different years to account for the variation of growth variables due to environmental factors. In the literature, different approaches to model the above ground tree biomass, 


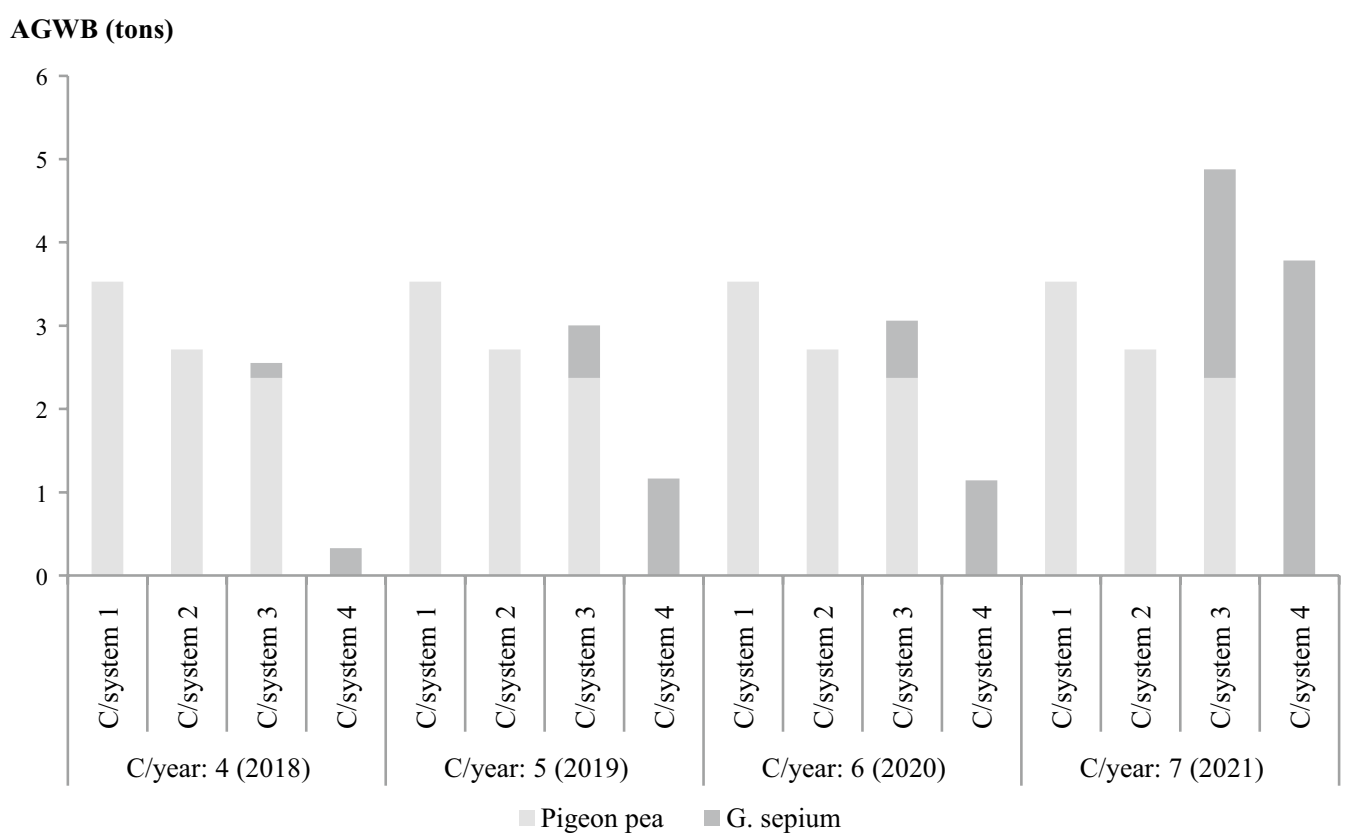

Fig. 5 Estimated total above-ground woody biomass production per hectare based on cropping systems 1-4 for the cropping years 4-7

such as non-linear allometric (power-law models) or linear (log-transformed models) models, are used [23, 35]. Following other scholars [25], we tested different allometric models and found that natural log-transformed models explain the variation of the AGWB production to a high degree. In forest science, log-transformed models using CFs for back-transformation of allometric relationships are common and reliable [36]. A CF is required to account for the estimation bias introduced during logtransformation; the usage of a correction factor enhances the accuracy of the model [29]. The developed models are suitable for estimating the AGWB production of pigeon pea and Gliricidia. However, external impacts, such as climate change, changes in temperatures, water availability and atmospheric $\mathrm{CO}_{2}$ affect plant growth in arid regions; something that has to be quantified in further studies [37].

With regard to the AGWB production of Gliricidia, our results show that a linear regression model with two explanatory variables (natural log-transformed $\mathrm{RCD}_{20}$ and natural log-transformed stem height) (Model 6) explains the variation of the AGWB production $\left(R^{2}=96.9 \%\right)$ best. However, $\mathrm{RCD}_{20}$ and stem height, the independent variables, show multicollinearity [38]. To resolve this issue, we constructed a composite variable of $\mathrm{RCD}_{20}$ and stem height (Model 7), which also estimated the AGWB very reliably $\left(R^{2}=96.8 \%\right)$. With regard to the AICs and $R^{2}$, models 6 and 7 have higher predictive values for estimating the AGWB production than model 4, but both models are based on two independent variables. Model 4 has a slightly lower explanatory power $\left(R^{2}=95.7 \%\right)$ but requires only one independent variable to predict the AGWB production. Considering the marginal loss of prediction value due to a single indicator, model 4 is recommended as a baseline model for estimating the AGWB of Gliricidia. This is in line with other authors who also indicate that stem diameter alone is the best indicator for estimating the stem biomass of trees [24]. For stakeholders, it might be more practical to assess one single dendrometric indicator $\left(\mathrm{RCD}_{20}\right)$ instead of multiple ones $\left(\mathrm{RCD}_{20}\right.$ and stem height), when estimating AGWB; assessing $\mathrm{RCD}_{20}$ instead of stem height is recommended as $R_{C D}$ can be non-destructively assessed using a caliper. The evaluation of stem height might be impractical in rural settings and might require the logging of the tree to assess the height [39].

The analysis of AGWB of pigeon pea stalks indicates similar results. Model 4 , using $\mathrm{RCD}_{20}$ as a single predictor variable, provided the highest degree of determination $\left(R^{2}=91.4 \%\right)$. This is in line with the AIC value, which also suggests that model 4 is the best one for predicting the AGWB. Similar to Gliricidia, multicollinearity is detected between $R_{C D}$ and stem height, thus suggesting that model 6 does not meet the statistical requirements of OLS [24]. Model 7 can also be rejected, because the degree of determination is lower compared to model 4 and because two independent variables must be assessed, thus increasing the workload. In line with other studies, 
we recommend using $\mathrm{RCD}_{20}$ as a single predictor for estimating the AGWB production. Meta studies in SSA indicate that $75 \%$ of the developed allometric equations are based upon stem diameter or circumference as predictors for estimating the AGWB; $74 \%$ of allometric equations are using a single predictor variable to estimate the AGWB production, thus also reducing statistical problems related to multicollinearity [31]. There is a debate whether site and species-specificity affect the validity of allometric biomass equations. Nelson et al. [40] suggested that site-specific variations might have an impact on dendrometric variables, such as stem dimensions, thus requiring adapted allometric models. As Gliricidia is planted in different planting regimes with regard to spacing and pruning time, it might be necessary to develop new models for different cropping and management systems. With regard to the differing management regimes of Gliricidia, with a growth length exceeding the annual pruning regime that was analysed in this study, the developed allometric models must be adapted. A sample size, exceeding 50 samples, is large enough to fit new allometric models acknowledging changed site conditions [41].

\section{Assessment of the above-ground woody biomass production of pigeon pea and Gliricidia}

With regard to Gliricidia production, our assessment shows that with cropping system 4 (MGS), more Gliricidia fuelwood would be produced than with cropping system 3 (MPPGS). The difference might be explained by the reduced competition between the plants in cropping system 4 , whereas in cropping system 3 , the number of crops was $50 \%$ higher. Studies revealed that higher plant density leads to a higher competition for resources, resulting in lower yields per plant [42]. During our assessment, similar results were found for pigeon pea with cropping system 1 (PP) showing higher plant survival rates than cropping systems 2 (MPP) and 3 (MPPGS), which both had higher plant densities. In addition, we found a larger $\mathrm{RCD}_{20}$ in cropping system 1, which was also connected with a higher AGWB production per area compared to cropping systems 2 and 3 . However, the AGWB production of pigeon pea depends on external factors and varies from year to year. The estimated AGWB production from pigeon pea is not warranted as the underlying assumptions vary. As shown for cropping years 5 and 6 , a comparison of the AGWB production per $\mathrm{m}^{2}$ as well as the plant survival rates vary significantly within the cropping systems, which may lead to inaccurate predictions. Further differences connected with different external factors (plot management, rainfall) might also contribute to those inaccuracies.
With regards to AGWB production of Gliricidia, we observed that the multi-annual pruning of Gliricidia shrubs is connected to a higher number of stems sprouting in the subsequent year, thus suggesting an increase in the AGWB production per plant over the years. This is in line with other studies demonstrating a positive effect of pruning on the number of stems per plant [43]. We coppiced the Gliricidia plants twice a year (first pruning was done at crop planting stage; second pruning was done around 2 months after planting). Our measured AGWB production per plant was in line with other studies, which indicated that 5 -year-old Gliricidia plants produced up to $33.9 \mathrm{~kg}$ tree ${ }^{-1}$ of fresh wood [44]. It needs to be emphasized that the AGWB production is directly connected with the number of Gliricidia stems sprouting after pruning. Further research is needed to determine the best copping regimes to maximise the AGWB production of Gliricidia. Simons and Stewart [45] suggested pruning intercropped Gliricidia plants at a height of $2 \mathrm{~m}$ to stimulate optimal fuelwood production. However, depending on the cropping system, this practice might not be suitable. Especially in intercropping scenarios with crops, it might be necessary to prune Gliricidia more frequently to avoid negative impacts, such as shading on neighbouring crops. Kaba and Abunyewa [46] reported that the optimum pruning regime for Gliricidia plants with regard to biomass production lies between 8 and 10 months. The produced fuel from Gliricidia and pigeon pea is a good substitute for off-farm fuelwood due to its comparably high calorific value and low smoke production during combustion [45]. Scientists estimated an average gross calorific value for different off-farm firewood species of $19.8 \mathrm{MJ} \mathrm{kg}^{-1}$ [47], while for a 5-year-old Gliricidia fuel and a fuel from pigeon pea $19.1 \mathrm{MJ} \mathrm{kg}-1$ [48] and $15.0 \mathrm{MJ} \mathrm{kg}^{-1}$ [49], respectively, were estimated.

Hafner et al. [50] compared the fuel consumption of on-farm produced Gliricidia (1.815 tons year ${ }^{-1}$ ) with $20 \%$ moisture content and pigeon pea (1.551 tons year ${ }^{-1}$ ) with $10 \%$ moisture content with the commonly used off-farm species Mimusops obtusifolia (2.273 tons year ${ }^{-1}$ ) with $20 \%$ moisture content when cooking a fast cooking meal using a TSF in the semi-arid Dodoma region in Tanzania. The authors reported that pigeon pea and Gliricidia required less fuel than the off-farm species. The annual consumption rates were estimated based upon an average household size of 5 to 6 members. However, the annual estimated fuel consumption patterns of Gliricidia and pigeon pea are based upon assumptions regarding cooking behaviours (fast cooking food items), household size (5 to 6 household members), as well as the frequency of cooking [50]. As these conditions might vary from household to household, the consumption patterns at the household level might vary as well. Comparing the 
suggested annual fuel requirements with the fuelwood production from our agroforestry trial, less than one hectare is required to cover the households' energy demand with pigeon pea or Gliricidia. For cropping year 7, which was the last year of our observation, we found that based on the assessed survival rates of pigeon pea and Gliricidia plants, 0.40 ha with cropping system 1 and 0.52 ha with cropping system 2 are required to meet the annual fuel demand for cooking. Assuming a fuel consumption distribution of $50 \%$ pigeon pea and Gliricidia, 0.30 ha with cropping system 3 would be needed to be energy-self-sufficient. With cropping system $4,0.40$ ha of Gliricidia are needed to meet household's energy demand. The results of this study demonstrate the potential of on-farm fuel production systems to meet households' energy demand and fuel autarky. However, the estimations of the AGWB production must be assessed carefully, as the underlying growth assumptions might vary depending on precipitation, temperature, pests and diseases among others.

\section{Adoption of on-farm fuel production systems}

In semi-arid Tanzania, smallholder farmers' food security is mainly based upon own agricultural production. Therefore, fuelwood production should not impair food production. Studies from the same research site showed that the integration of Gliricidia and pigeon pea in cropping plans does not lead to crop yield loss but bears the potential to yield more using less area (sustainable intensification) [51, 52]. The introduction of agroforestry systems needs to consider the whole crop/tree value chain, including the availability of seeds, the availability of seedlings, the growth rates, the local interests, as well as the marketability of the product [8]. The management of the research plot was supervised by researchers; therefore, the current management practices might be different when farmers manage agroforestry farms without constant extension services. Nevertheless, a broad uptake of on-farm wood production at the household level is needed to achieve fuelwood autarky for communities. A study in Malawi indicated that the decision to plant onfarm trees is mainly made by male household heads; with the highest tree density achieved when the trees were jointly managed by men and women [53]. With regard to pigeon pea, scientists cited that the decision to plant pigeon pea is connected to the expected market prices for pigeon pea grains [54]. The results showed that the AGWB production from cash crops, such as pigeon pea, is stable and can significantly contribute to households' cooking energy demand. However, if market prices for the crop are insecure, farmers might refrain from incorporating pigeon pea in their cropping plans.

Farmers with short-term preferences for fuel might opt for pigeon pea due to the fact that fuel production from Gliricidia requires multiple years. As shown in this research study, the substantial contribution of Gliricidia toward households' energy demand from on-farm fuel production can only be expected after several years of growth, which might limit its uptake by smallholder farmers, because a quick contribution toward the households' energy mix cannot be expected. High upfront investment costs incurred before Gliricidia systems significantly add to households' energy mix might limit the adoption of agroforestry systems to long-term oriented farmers. Additional factors underlying non-adoption of Gliricidia-based agroforestry systems at the smallholder level include a lack of access to extension services, training and financing [55]. Thangata and Alavalapati [56] reported that farmers' age is negatively, while the number of farm workers is positively correlated to the adoption of Gliricidia-based agroforestry systems. Coulibaly et al. [57] showed that the amount of land owned as well as the available financial resources are connected with the adoption of agroforestry systems. Foliage and green manure production from Gliricidia is not highlighted in this study. However, it is important to consider multiple benefits of foliage production from agroforestry systems when discussing the adoption. Specifically, increased organic matter and reduced carbon-nitrogen ratios enhance soil fertility [58]. Chirwa et al. [59] determined an increase in mineral nitrogen and enhanced nitrogen uptake of green leaf manure of Gliricidia substituting nitrogen-based mineral fertilizers. Especially in remote areas, smallholder farmers might have limited access to cost-intensive mineral fertilizers. Adoption of agroforestry systems might be encouraged via improved access to credit, stable market prices for pigeon pea (e.g., through subsidies), as well as enhanced training of smallholder farmers and extension officers on the benefits of agroforestry systems.

\section{Conclusion}

In this study, we quantified the AGWB production from four Gliricidia and pigeon pea intercropping systems under semi-arid conditions. The developed allometric equations help to estimate the on-farm fuel production potential of smallholder farmers to optimize local agricultural production programmes. The comparison of fuel production with literature-based household fuel consumption patterns indicated that on-farm fuel production systems might substantially cover a household's fuel demand, ultimately leading to complete fuel autarky. To apply the developed allometric equations, stakeholders are required to only measure the single variable, $\mathrm{RCD}_{20}$, within a cross sectional area and fill the resulting data into the recommended formulae to reliably predict the AGWB production from pigeon pea and Gliricidia. 
Assessing an additional variable, such as stem height, is not necessary as it only marginally affects the explanatory value of the tested allometric models. The suggested Gliricidia and pigeon pea systems can be implemented by smallholder farmers, as less than one hectare is needed to meet the annual energy demand of an average-sized household. Annual growth of Gliricidia and pigeon pea depends on multiple factors, such as farm management and environmental factors. More research is needed to understand the main drivers of Gliricidia and pigeon pea growth to optimize the estimation of the AGWB production. To obtain benefits of agroforestry systems, the identification of drivers of dissemination as well as determinants of adoption of Gliricidia and pigeon pea systems is vital. On site practitioners should not neglect the importance of capacity building at the local level. Enhancing local knowledge on seedling production, disease management and tree pruning practices might stimulate the usage of pigeon pea and Gliricidia intercropping systems.

\section{Acknowledgements \\ The views expressed in this paper are purely those of the authors and may not under any circumstances be regarded as an official position of USAID and USDA. Special thanks goes to the Leibniz Centre for Agricultural Landscape Research (ZALF) in Müncheberg, Germany, and to World Agroforestry (ICRAF) Tanzania for their logistical support in conducting the research in Dodoma region, Tanzania. The anonymous reviewers are thanked for their valuable recommendations}

\section{Authors' contributions}

JMH developed the work plan for data collection and adapted the methodology to fit the research purpose. JMH analysed the data and drafted the different sections of the paper. AK contributed to the theoretical conceptualization of data collection. AK, GU, JS and StS contributed to the literature review and discussion parts of the manuscript. All authors read and approved the final manuscript.

\section{Funding}

This paper is based on data collected from the research experiment at Manyusi, Dodoma region, Tanzania, established with support from the Africa RISING programme, which partially funded the fieldwork. The article publication charges were covered by the Africa RISING project. The United States Agency for International Development's (USAID) Feed the Future initiative funded the Africa RISING programme. Field operations of the first author were co-financed by the United States Department of Agriculture (USDA) through the USAID funded project on Capacity Building for Resilient Food Security Project in Tanzania.

\section{Availability of data and materials}

The data sets used and/or analysed during the current study are available from the corresponding author on reasonable request.

\section{Declarations}

Ethics approval and consent to participate Not applicable.

\section{Consent for publication}

Not applicable.

\section{Competing interests}

The authors declare that they have no competing interests.

\section{Author details}

${ }^{1}$ Leibniz Centre for Agricultural Landscape Research (ZALF), Research Area "Land Use and Governance", Eberswalder Str. 84, 15374 Müncheberg, Germany. ${ }^{2}$ World Agroforestry (ICRAF), ICRAF Country Programme, TARI Mikocheni, P.O. Box 6226, Dar es Salaam, United Republic of Tanzania.

${ }^{3}$ Thaer-Institute of Agricultural and Horticultural Sciences, Humboldt University Berlin, Berlin, Germany.

Received: 13 July 2021 Accepted: 28 September 2021

Published online: 08 November 2021

\section{References}

1. TFS (2015) National Forest Resources Monitoring and Assessment of Tanzania Mainland: MAIN RESULTS

2. Scheid A, Hafner JM, Hoffmann H et al (2019) Adapting to fuelwood scarcity: the farmers' perspective. Front Sustain Food Syst 3:28

3. Kulindwa YJ, Lokina R, Ahlgren EO (2018) Driving forces for households' adoption of improved cooking stoves in rural Tanzania. Energ Strat Rev 20:102-112

4. Waswa F, Mcharo M, Mworia M (2020) Declining wood fuel and implications for household cooking and diets in Tigania Sub-County Kenya. Scientific African 1:e00417

5. Felix M, Gheewala SH (2011) A review of biomass energy dependency in Tanzania. Energy procedia 9:338-343

6. Kahyarara G (2017) Trends in population growth and forest cover change in Tanzania (From 1980 Until 2018). Tanzania J Popul Stud Dev 15:1

7. Funk CC, Brown ME (2009) Declining global per capita agricultural production and warming oceans threaten food security. Food Security 1:271-289

8. Tremblay S, Lucotte M, Revéret J-P et al (2015) Agroforestry systems as a profitable alternative to slash and burn practices in small-scale agriculture of the Brazilian Amazon. Agrofor Syst 89:193-204

9. Rowhani $\mathrm{P}$, Lobell DB, Linderman M et al (2011) Climate variability and crop production in Tanzania. Agric For Meteorol 151:449-460

10. Doggart N, Morgan-Brown T, Lyimo E et al (2020) Agriculture is the main driver of deforestation in Tanzania. Environ Res Lett 15:34028

11. Glover JD, Reganold JP, Cox CM (2012) Plant perennials to save Africa's soils. Nature 489:359-361

12. Smethurst PJ, Huth NI, Masikati P et al (2017) Accurate crop yield predictions from modelling tree-crop interactions in gliricidia-maize agroforestry. Agric Syst 155:70-77

13. Gibbs HK, Brown S, Niles JO et al (2007) Monitoring and estimating tropical forest carbon stocks: making REDD a reality. Environ Res Lett 2:45023

14. Githiomi JK, Oduor N (2012) Strategies for sustainable wood fuel production in Kenya

15. Ali A, Mottaleb KA, Aryal JP (2019) Wealth, education and cooking-fuel choices among rural households in Pakistan. Energy Strat Rev 24:236-243

16. Moore JR (2010) Allometric equations to predict the total above-ground biomass of radiata pine trees. Ann For Sci 67:806

17. Pinto AA, Zilberman D (2017) Modeling, dynamics, optimization and bioeconomics II: DGS III, Porto, Portugal, February 2014, and Bioeconomy VII, Berkeley, USA, March 2014-Selected Contributions. Springer

18. Jucker T, Caspersen J, Chave J et al (2017) Allometric equations for integrating remote sensing imagery into forest monitoring programmes. Glob Change Biol 23:177-190

19. Mahmood H, Hosen MF, Siddiqui MRH et al (2020) Allometric biomass model for Aquilaria malaccensis Lam. in Bangladesh: a nondestructive approach. J Sustain For 40:1-13

20. Ketterings QM, Coe R, van Noordwijk M et al (2001) Reducing uncertainty in the use of allometric biomass equations for predicting above-ground tree biomass in mixed secondary forests. For Ecol Manage 146:199-209

21. Basuki TM, van Laake PE, Skidmore AK et al (2009) Allometric equations for estimating the above-ground biomass in tropical lowland Dipterocarp forests. For Ecol Manage 257:1684-1694

22. Fayolle A, Ngomanda A, Mbasi M et al (2018) A regional allometry for the Congo basin forests based on the largest ever destructive sampling. For Ecol Manage 430:228-240 
23. Kimaro AA, Timmer VR, Chamshama SAO et al (2009) Competition between maize and pigeonpea in semi-arid Tanzania: effect on yields and nutrition of crops. Agr Ecosyst Environ 134:115-125

24. Dimobe K, Goetze D, Ouédraogo A et al (2019) Aboveground biomass allometric equations and carbon content of the shea butter tree (Vitellaria paradoxa CF Gaertn., Sapotaceae) components in Sudanian savannas (West Africa). Agrofor Syst 93:1119-1132

25. Fordjour PA, Rahmad ZB (2013) Development of allometric equation for estimating above-ground liana biomass in tropical primary and second ary forest, Malaysia. Hindawi Publishing Corporation. Int J Ecol 2013:1-8

26. Kassile T (2013) Trend analysis of monthly rainfall data in central zone. J Math Stat 9:1

27. Akaike H (1974) A new look at the statistical model identification. IEEE Trans Autom Control 19:716-723

28. Kebede B, Soromessa T (2018) Allometric equations for aboveground biomass estimation of Olea europaea L. subsp. cuspidata in Mana Angetu Forest. Ecosyst Health Sustain 4:1-12. https://doi.org/10.1080/20964129. 2018.1433951

29. Baskerville GL (1972) Use of logarithmic regression in the estimation of plant biomass. Can J For Res 2:49-53

30. Sprugel DG (1983) Correcting for bias in log-transformed allometric equations. Ecology 64:209-210

31. Henry M, Picard N, Trotta C et al (2011) Estimating tree biomass of subSaharan African forests: a review of available allometric equations. Silva Fennica 45:477-569

32. Nordh N-E, Verwijst T (2004) Above-ground biomass assessments and first cutting cycle production in willow (Salix sp.) coppice-a comparison between destructive and non-destructive methods. Biomass Bioenergy 27:1-8

33. Lu D, Chen Q, Wang G et al (2016) A survey of remote sensing-based aboveground biomass estimation methods in forest ecosystems. Int J Digital Earth 9:63-105

34. Vashum KT, Jayakumar S (2012) Methods to estimate above-ground biomass and carbon stock in natural forests-a review. J Ecosyst Ecogr 2:1-7

35. Paul Kl, Roxburgh SH, Chave J et al (2016) Testing the generality of aboveground biomass allometry across plant functional types at the continent scale. Glob Change Biol 22:2106-2124

36. Clifford D, Cressie N, England JR et al (2013) Correction factors for unbiased, efficient estimation and prediction of biomass from log-log allometric models. For Ecol Manage 310:375-381

37. Liu M, Xu X, Jiang Y et al (2020) Responses of crop growth and water productivity to climate change and agricultural water-saving in arid region. Sci Total Environ 703:134621

38. Mahmood H, Siddique MRH, Costello L et al (2019) Allometric models for estimating biomass, carbon and nutrient stock in the Sal zone of Bangladesh. iForest-Biogeosci For 12:69

39. Peichl M, Arain MA (2006) Above- and below-ground ecosystem biomass and carbon pools in an age-sequence of temperate pine plantation forests. Agric For Meteorol 140:51-63

40. Nelson BW, Mesquita R, Pereira JLG et al (1999) Allometric regressions for improved estimate of secondary forest biomass in the central Amazon. For Ecol Manage 117:149-167

41. Paul KI, Radtke PJ, Roxburgh SH et al (2018) Validation of allometric biomass models: how to have confidence in the application of existing models. For Ecol Manage 412:70-79

42. Zhai L, Li H, Song S et al (2021) Intra-specific competition affects the density tolerance and grain yield of maize hybrids. Agron J 113:224-235
43. Goldenberg MG, Oddi FJ, Amoroso MM et al (2020) Effects of harvesting intensity and site conditions on biomass production of northern Patagonia shrublands. Eur J Forest Res 139:881-891

44. Atapattu A, Pushpakumara D, Rupasinghe WMD et al (2017) Potential of Gliricidia sepium as a fuelwood species for sustainable energy generation in Sri Lanka. Agric Res J 54:34-39

45. Simons A, Stewart J (1994) 2.2 Gliricidia sepium-a multipurpose forage tree legume

46. Kaba JS, Abunyewa AA (2019) New aboveground biomass and nitrogen yield in different ages of gliricidia (Gliricidia sepium Jacq.) trees under different pruning intensities in moist semi-deciduous forest zone of Ghana. Agrofor Syst 1:1-8

47. Eberhard AA (1990) Fuelwood calorific values in South Africa. S Afr For J 152:17-22

48. Orwa C, Mutua A, Kindt R et al. (2009) Agroforestree Database: a tree reference and selection guide. Version 4. Agroforestree Database: a tree reference and selection guide. Version 4

49. Katyal SK, lyer PVR (2000) Thermochemical characterization of pigeon pea stalk for its efficient utilization as an energy source. Energy Sources 22:363-375

50. Hafner JM, Uckert G, Hoffmann HK et al (2020) Efficiency of three-stone fire and improved cooking stoves using on-farm and off-farm fuels in semi-arid Tanzania. Energy Sustain Dev 59:199-207

51. Renwick LLR, Kimaro AA, Hafner JM et al (2020) Maize-pigeonpea intercropping outperforms monocultures under drought. Front Sustain Food Syst 4:253

52. Pretty J (2018) Intensification for redesigned and sustainable agricultural systems. Science 362:1

53. Meijer SS, Sileshi GW, Kundhlande G et al (2015) The role of gender and kinship structure in household decision-making for agriculture and tree planting in Malawi. J Gender Agric Food Secur Agri-Gender 1:54-76

54. Orr A, Kambombo B, Roth C et al (2015) Adoption of integrated foodenergy systems: improved cookstoves and pigeonpea in southern Malawi. Exp Agric 51:191-209

55. Maliki R, Sinsin B, Parrot L et al. (2017) Sustainable Agroforestry Adoption in a Small-Scale Food Production System: the Case of Yam in Rotation with the Intercropping Gliricidia Sepium and Herbaceous in the GuineaSudan Zone of Benin

56. Thangata PH, Alavalapati JRR (2003) Agroforestry adoption in southern Malawi: the case of mixed intercropping of Gliricidia sepium and maize. Agric Syst 78:57-71

57. Coulibaly JY, Chiputwa B, Nakelse T et al (2017) Adoption of agroforestry and the impact on household food security among farmers in Malawi. Agric Syst 155:52-69

58. Beedy TL, Snapp SS, Akinnifesi FK et al (2010) Impact of Gliricidia sepium intercropping on soil organic matter fractions in a maize-based cropping system. Agr Ecosyst Environ 138:139-146

59. Chirwa PW, Black CR, Ong CK et al (2006) Nitrogen dynamics in cropping systems in southern Malawi containing Gliricidia sepium, pigeonpea and maize. Agrofor Syst 67:93-106

\section{Publisher's Note}

Springer Nature remains neutral with regard to jurisdictional claims in published maps and institutional affiliations. 